\title{
Presurgical Evaluation and Epilepsy Surgery in MRI Negative Resistant Epilepsy of Childhood with Good Outcome
}

\author{
MRG Negatif Dirençli Epilepsisi olan Çocuklarda Cerrabi Öncesi \\ Değerlendirme ve Epilepsi Cerrabisi
}

\author{
Dana CRAIU ${ }^{1,2^{*}}$, Andrei BARBORICA ${ }^{3,4^{*}}$ Cristina MOTOESCU ${ }^{1,2^{*}}$, Cristian DONOS ${ }^{3 *}$, Jean CIUREA ${ }^{5,3}$, \\ Ioana MINDRUTA $1,3,6^{*}$ \\ 1 "Carol Davila" University of Medicine Bucharest, Department of Neurology, Pediatric Neurology, Psychiatry, Neurosurgery Discipline, \\ Bucharest, Romania \\ 2"Alexandru Obregia” Clinical Psychiatric Hospital, Pediatric Neurology Clinic, Şos. Berceni 10- 12, Sector 4, Bucharest, Romania \\ ${ }^{3}$ University of Bucharest, Physics Department, Bucharest, Romania \\ ${ }^{4} \mathrm{FHC}$ Inc, Bowdoin ME, USA \\ ${ }^{5}$ Bagdasar Arseni Emergency Hospital, Functional Neurosurgery Department, Şos. Berceni 14-16, Sector 4, Bucharest, Romania \\ ${ }^{6}$ University Emergency Hospital Bucharest, Neurology Clinic, Str. Splaiul Independenței Nr 169, Sector 5, Bucharest, Romania \\ *Dana CRAIU, Andrei BARBORICA, Cristina MOTOESCU, Cristian DONOS and Ioana MINDRUTA are contributed equally to this work.
}

Corresponding Author: Dana CRAIU / E-mail: dcraiu@yahoo.com

To watch the surgical videoclip, please visit http://turkishneurosurgery.org.tr/images/12093_video.mp4

\begin{abstract}
Magnetic resonance imaging (MRI)-negative epilepsy may be successfully solved with a multidisciplinary approach using invasive recordings, image and signal analysis. The whole methodology used by the epilepsy surgery team is systematically described based on an resistant epilepsy case with all steps and rationale of choosing different investigation methods from surface electroencephalography (EEG) to invasive recordings. Due to negative MRI and non-concordant ictal surface EEG with clinical semiology, the patient was investigated with stereoEEG (SEEG), aiming to delimitate epileptogenic and eloquent cerebral areas. Implantation strategy, seizures recordings, stimulation, resection planning using quantitative EEG analysis, and the surgery plan are presented. The patient has been seizure-free for 14 months so far, with improved behavior and daily life quality. Post-operative examination revealed focal cortical dysplasia type II B.
\end{abstract}

KEYWORDS: Epilepsy surgery, Focal cortical dysplasia, MRI-negative postsurgical outcome, Resistant epilepsy, Stereo-EEG

öz

Manyetik rezonans görüntüleme (MRG)-negatif epilepsi, invaziv kayıt alma, görüntü ve sinyal analizini kapsayan mültidisipliner bir yaklaşımla başarılı bir şekilde tedavi edilebilir. Dirençli bir epilepsi olgusu temelinde epilepsi cerrahisi ekibinde kullanılan tüm metodoloji tüm basamakları ile, yüzey elektroensefalografisinden (EEG) invaziv kayıt almaya kadar değişik inceleme teknikleri arasından uygun olanı seçilerek, tanımlanmıştır. Olgu MRG negatif olduğu ve klinik tablo ile iktal yüzey EEG uyumsuz olduğu için stereo-EEG (SEEG) kullanılarak epileptojenik bölgeler ile fonksiyonel beyin alanlarının ayırt edilmesi hedeflenmiştir. Bu olgunun implantasyon stratejisi, nöbet kayıtları, stimülasyon, kantitatif EEG analizi ile rezeksiyon planlaması ve cerrahi planı sunulmuştur. Hastada 14 ay boyunca nöbet izlenmemiştir, davranışları ve günlük yaşam kalitesi düzelmiştir. Postoperatif inceleme Tip II B fokal kortikal displazi olduğunu göstermiştir.

ANAHTAR SÖZCÜKLER: Epilepsi cerrahisi, Fokal kortikal displazi, MRG-negatif cerrahi sonrası sonuç, Dirençli epilepsi, Stereo-EEG

\section{INTRODUCTION}

Epilepsy affects $0.6 \%$ of the world population. $30-40 \%$ of patients are resistant to antiepileptic drugs (AEDs) (14) and about $30 \%$ of them are potential candidates for epilepsy surgery (4). For the Romanian population, 0.6\% (129000 persons) have active epilepsy (10), with 38700 patients resistant to AEDs and 12900 potential candidates for epilepsy surgery. Big differences exist in clinical practice between regions of the world, with a few developing countries having viable epilepsy surgery programs $(8,11)$. Magnetic resonance imaging (MRI)-negative epilepsy cases are recently being operated using invasive presurgical evaluation techniques (3). We present the protocol used by our multidisciplinary team 
for investigation of MRI-negative cases exemplified on a AEDs resistant case with focal cortical dysplasia (FCD), associated with negative MRI (at 1.5T investigation) and with nonconcordant surface ictal electroencephalography (EEG) with the clinical onset, as cited in the literature (13). Intracranial systematic exploration, based on previous non-invasive presurgical investigation, allowed an accurate delineation of the epileptogenic area and eloquent cortex using both classical methods and quantitative EEG analysis used to create topographic activity maps, leading to successful surgery outcome (seizure freedom and lack of neurological deficits).

\section{CASE REPORT}

A 17-year-old right-handed female patient with resistant epilepsy with onset at age 4 years is presented. Her personal and family history was unremarkable concerning development, epilepsy/febrile seizures or epilepsy etiology. She had a normal intellect and neurological examination.

Seizures and treatment. Her seizures, unchanged over time, occurred in clusters mostly during sleep, with bilateral tonic-asymmetric posture, followed by right body clonic movements, head version towards right, drooling, duration under 1 minute, postictal aphasia of short duration (2-5 minutes), no postictal motor deficit. Some seizures were preceded right arm tingling/paresthesia. Semiological analysis pointed to frontal supplementary sensorimotor area (SSMA) for the motor pattern, but a sensitive sensation onset of some seizures raised the working hypothesis of a postcentral (parietal) seizures origin. Different AEDs have been tried with reduced/short-lasting effect. Seizures became very frequent (30-40/day) followed by depression and behavioral disturbances (aggressiveness).

Neurological examination was normal. She was referred for presurgical evaluation for epilepsy surgery to our Pediatric Neurology Clinic.

EEG recordings. Recording of awake and sleep spontaneous interictal activity and habitual seizures were performed during five surface video-EEG sessions ( 8 hours to 2 days each).

Interictal EEG showed slow background (theta-delta range), especially when patient had 30-40 seizures/day, with sharp waves and spikes over the left frontal area, increased by sleep (Figures 1A, B).

Ictal EEG - showed frontal bilateral electrodecrement, predominantly left, followed by left frontal fast $>14 \mathrm{~Hz}$ activity and muscle artifact over the right lines corresponding to the tonic asymmetric posturing and right version of the head. Fp1-F3 and Fp1-F7 $2.5 \mathrm{~Hz}$ built-up rhythm, also visualized in the right frontal lines with a smaller amplitude (Fp2-F4, Fp2-F8) followed by high amplitude rhythmic movement artifacts corresponding to bilateral tonic asymmetric posturing and right side clonic movements. The slow postictal left frontal rhythm points to the origin of discharge (Figures 1C-F) (9).

Imaging. Three brain 1.5T MRI performed from 4 to 17 years were all normal (Figure 6A).
Psychological evaluation. Two cognitive evaluations at 14 and 16 years of age were performed showing normal levels for age (IQ 85). No complex neurocognitive presurgical evaluation was possible, because of severe behavioral changes, aggressiveness and lack of cooperation as a result of around 40 seizures/day.

Presurgical evaluation analysis. The hypothesis of a FCD was raised due to the unchanged aspect of the seizures over 12 years. The ictal semiology suggested SSMA left frontal lobe (dominant hemisphere) ictal onset, supported by interictal and ictal EEG. Several elements indicated further investigation with stereo-EEG (SEEG) method: negative MRI; the onset of some seizures with the aura described above, suggesting possible more posterior (parietal) ictal onset; interictal epileptiform activity visible also in left posterior areas. The aim of SEEG was to clearly indicate the limits of surgical resection by delineating with higher accuracy the epileptogenic zone, and the eloquent cortex to be preserved during surgery.

Implantation strategy used data offered by semiology and the standard surface video-EEG recordings (concordant clinical, interictal and ictal information). Premotor or postcentral territories may be associated with both tonic asymmetric motor pattern and also with the described aura. Left side lateralization was decided based on postictal aphasia and non-invasive interictal and early ictal EEG changes over the left (dominant) hemisphere. These areas were implanted with depth electrodes and explored systematically according to the principles of the SEEG methods (12). Ethical hospital approval and patient informed consent were obtained.

We used $0.8 \mathrm{~mm}$ diameter electrodes with 8-18 contacts (Dixi Microtechologies, Besançon, France) exploring both superficial and deep situated structures in a 3D approach (12). Dorsolateral and mesial territories were targeted with electrodes placed in superior, medium, and inferior frontal gyri, cingulate gyrus (Figure 2A-D). Dorsolateral perisylvian electrodes reached insula through their internal contacts. Orthogonal electrodes in the hand area in the motor cortex and inferior parietal lobule also explored the mesial frontoparietal structures (supplementary sensory-motor area, paracentral lobule, postcentral internal parietal cortex). Parasagittal territories were sampled with an oblique approach using electrodes that targeted the cingulate gyrus with the internal contacts (anterior, medium and posterior). The entire surgical planning and stereotactic coordinates were obtained using Waypoint Navigator (FHC Inc, Bowdoin, ME) software.

Implantation. The implantation was performed in the Functional Neurosurgery Department. The implantation protocol included: 1. Planning the electrodes trajectories according to the initial hypothesis, using the neuronavigation software, based on conventional MRI, several days before the implantation. 2. A contrast-enhanced MRI, T1 weighted with thin cuts $(1 \mathrm{~mm}$ ) was performed to visualize vascular network and co-registered with the structural MRI in the 

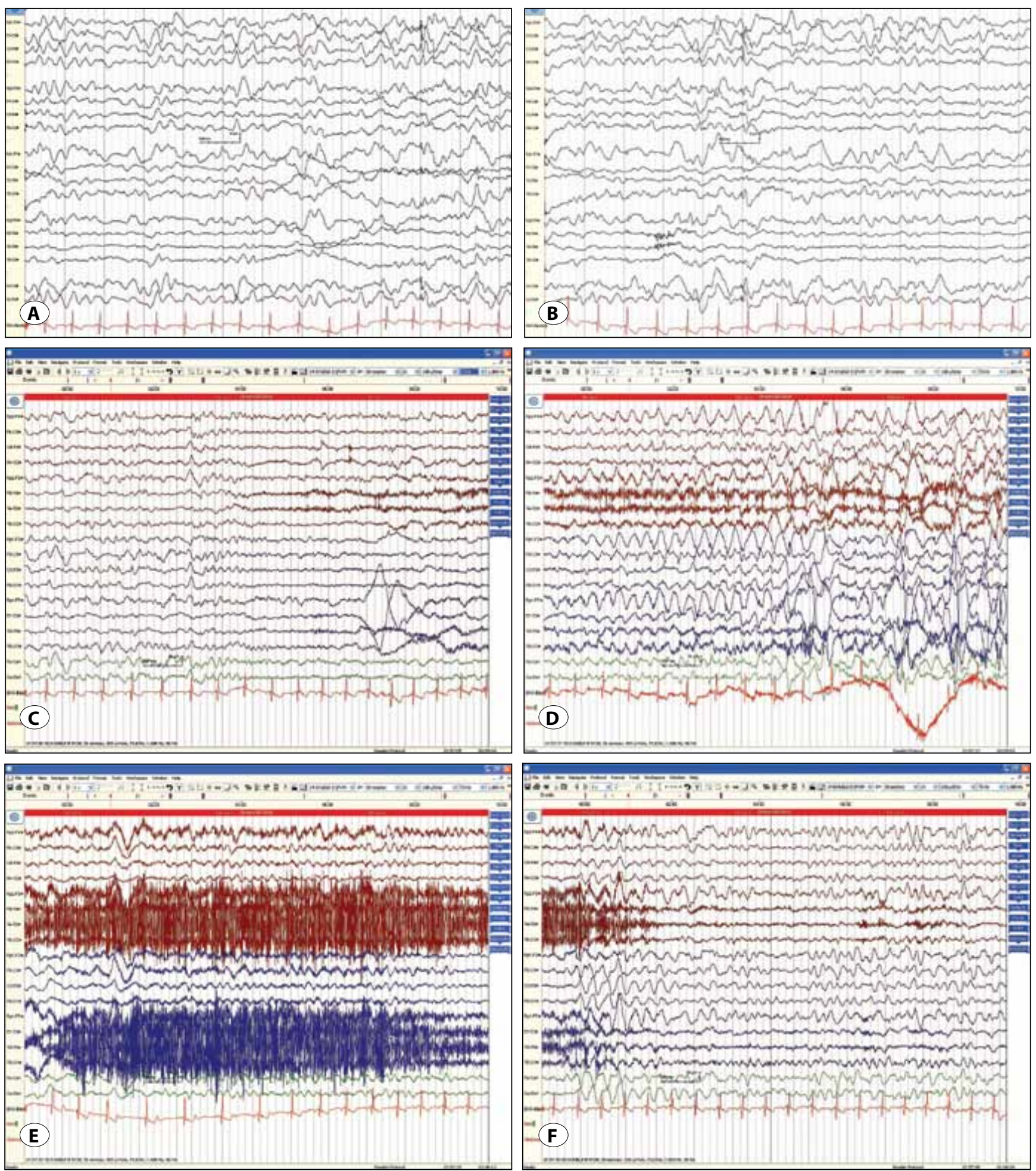

Figure 1: A, B) Interictal noninvasive EEG. Slow background in the theta-delta range, left more than right; interictal spikes, sharpwaves over the anterior Frontal lines, maximum F3-C3; C, D, E, F Ictal EEG) frontal bilateral electrodecrement, left more than right; followed by fast rhythms left frontal and muscle artifact over the right lines corresponding to the tonic asymmetric posturing and right version of the head (C); Fp1-F3 and Fp1-F7 2,5 Hz built-up rhythm (growing amplitude), also visualized in the right frontal lines with a smaller amplitude (Fp2-F4, Fp2 - F8) corresponding to bilateral tonic asymmetric posturing (D); high amplitude rhythmic movement artifacts (due to right limbs clonic movements $(\mathbf{D}, \mathbf{E})$; to the end of the seizure - bilateral muscle artifact over the temporal lines $(\mathbf{C}, \mathbf{D})$; postictal slowing over the left frontal lines (F). 
neuronavigation software. A digital angiographic image (MRA) was obtained by digitally filtering the contrast-enhanced MRI using a Frangi vesselness filter (6). A surface reconstruction of the vasculature was represented, along with the electrode trajectories (Figure 3A). A safety index that quantifies the proximity of the blood vessels along the trajectory (Figure
3B) was calculated (1) 3. Electrode trajectories were adjusted for maximizing the vascular safety index. 4. Preoperatively, a Leksell stereotactic frame was positioned on the patient's head, followed by a CT scan, used for frame registration. 5. $2 \mathrm{~mm}$ diameter burr holes were percutaneously drilled in the skull and the dura mater was punctured using an
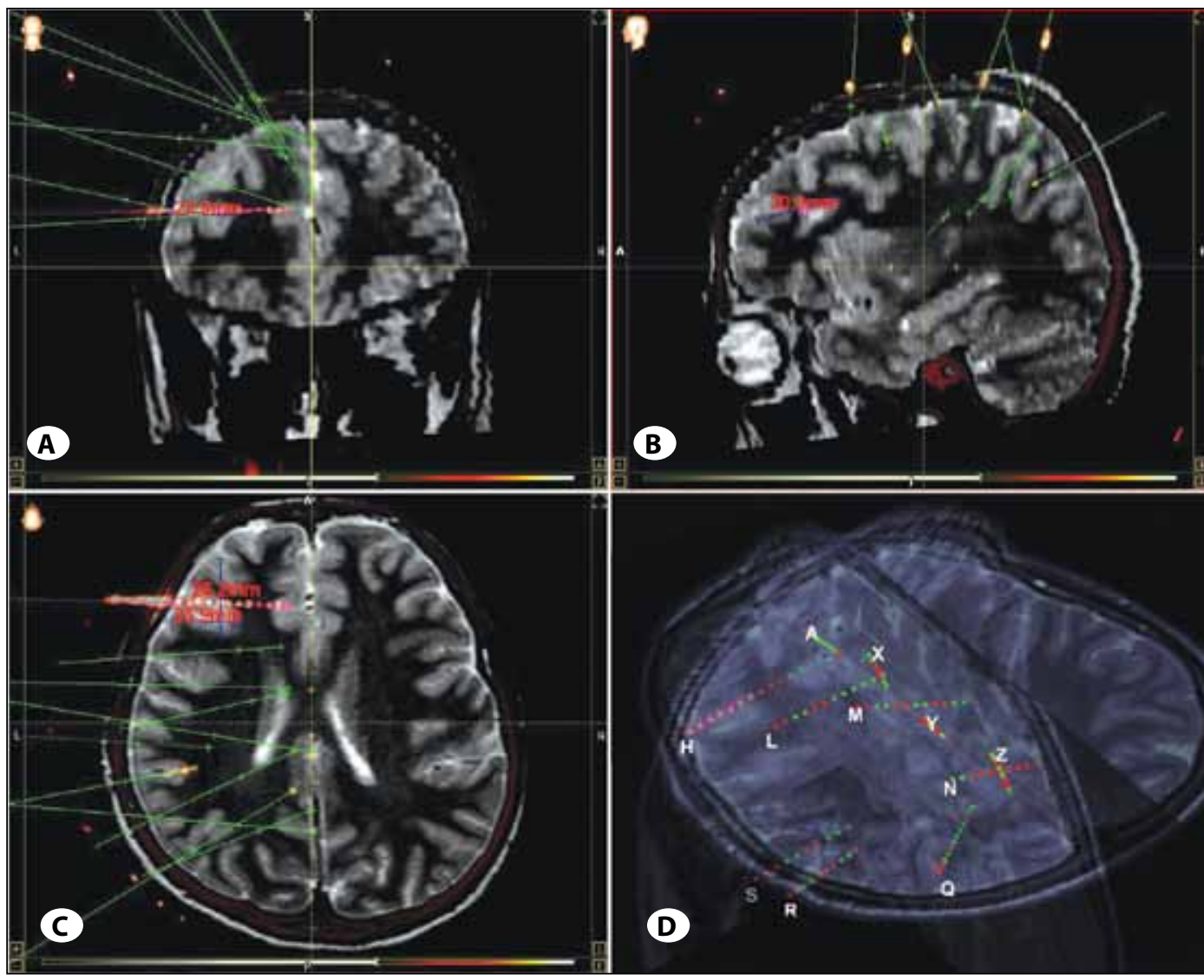

Figure 2: Left

hemisphere

implantation

scheme covering

premotor, motor and

parietal cortex both

dorsolateral and

mesial and resection

planning: A) T2

coronal view; B) T2

Sagittal view; C) T2

axial view; (for a., b.,

c.: trajectories of the

electrodes=green;

electrode $\mathrm{H}=$ purple);

D) 3D view of the

implanted electrodes

(for d.: green=contacts

stimulated/recorded

during the SEEG

investigation; green surrounded by purple - dysplastic gyrus).
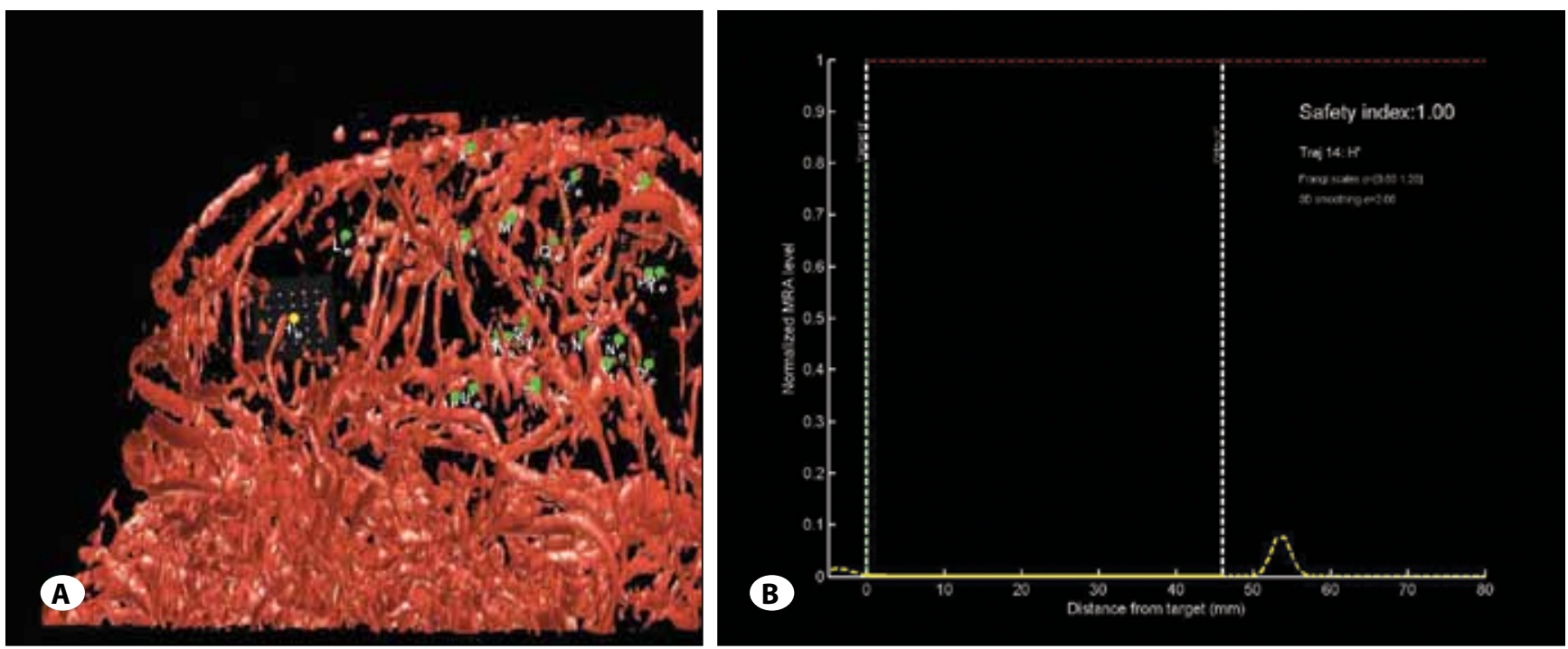

Figure 3: A) 3D reconstruction of the vascular network obtained by digitally filtering the contrast-enhanced MRI and electrodes trajectories (view aligned with $\mathrm{H}$ electrode trajectory); B) Safety index for $\mathrm{H}$ trajectory. Dashed lines indicate the position of the target and entry point. The peak at $53 \mathrm{~mm}$ from target corresponds to a blood vessel on the scalp. 
electrocoagulation electrode. Anchor bolts were placed in the burr-holes and an electrode path was created in the brain tissue using a rigid stylet. Electrodes were inserted and tightly secured to the anchor bolt with caps, to avoid cerebrospinal fluid (CSF) leakage and electrodes movements. 6. A post-implantation computed tomography (CT) scan was performed to confirm electrode positioning and to check for possible implantation complications. 7. The actual stereotactic coordinates of the electrodes were determined in the neuronavigation software, by co-registering the postimplantation CT scan with the pre-implantation MRI (Figure
$6 \mathrm{~A})$. The electrodes were checked using short EEG recordings. Finally 11 electrodes ( 128 recording contacts) were implanted.

Invasive recording procedure. The invasive recordings of spontaneous interictal activity and habitual seizures were performed in the Epilepsy Monitoring Unit for 10 days using a 64-channel EEG Wireless Amplifier, (4096 Hz sampling frequency, no filtering). The reference was located in the white matter. The contacts located in the white matter or noninformative were excluded. 64 contacts were recorded in the final montage (see also Supplementary material).

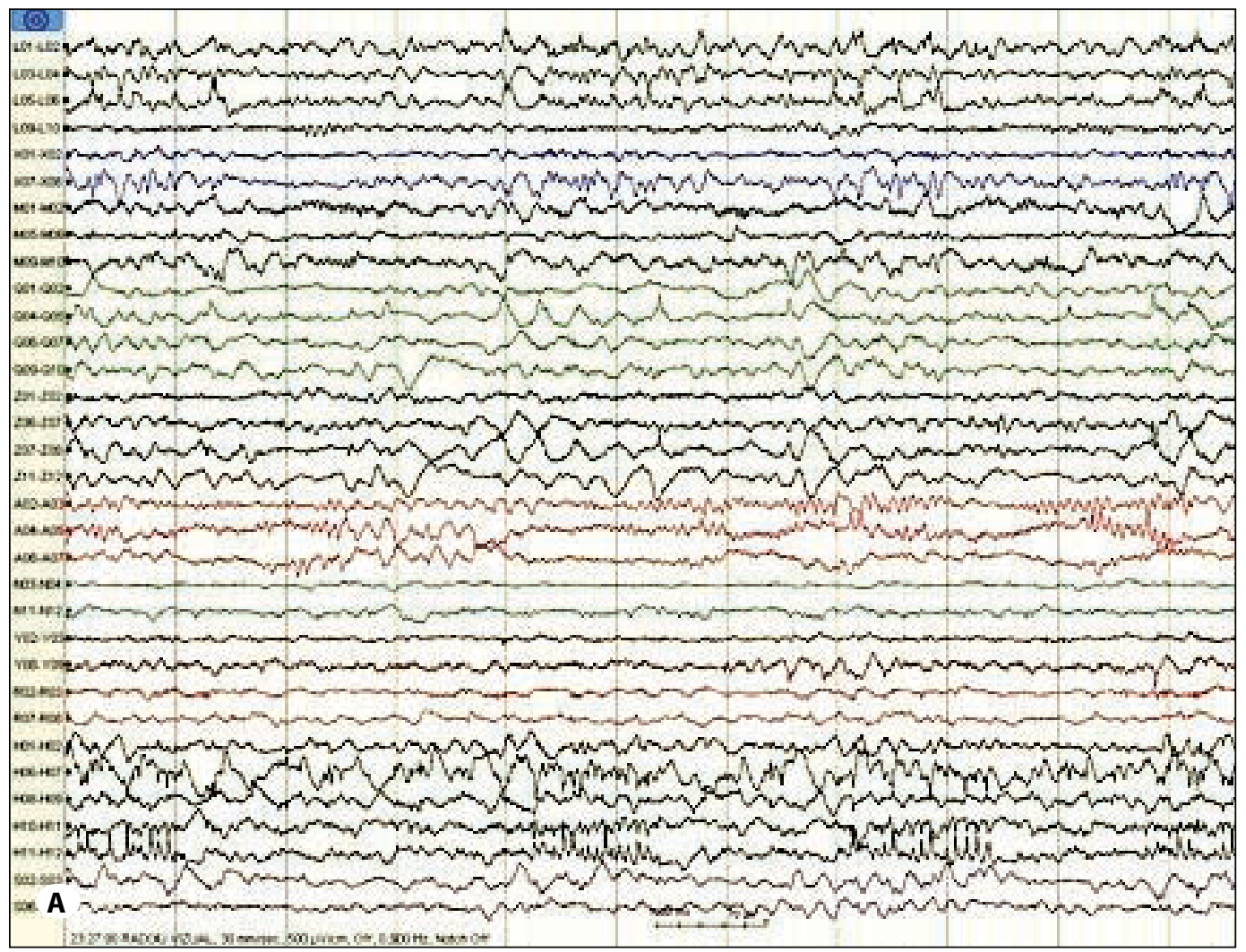

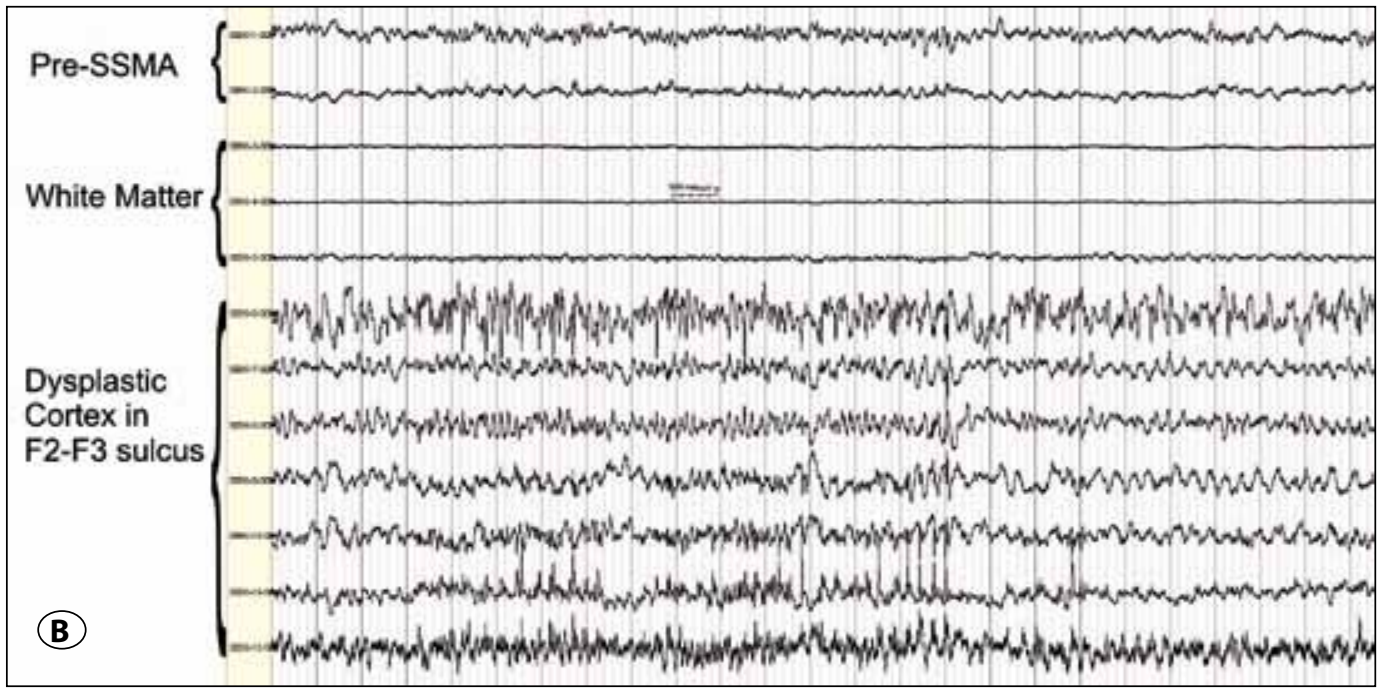

Figure 4: A) Interictal SEEG: bursts of spiking mixed with slowing during light sleep period in electrode $\mathrm{H}$ (contacts 6-12); B) Interictal electrical activity - $\mathrm{H}$ electrode. Continuous spiking over lines 6-12, exploring the premotor cortex, suggest a focal cortical dysplasia type II. Contact 6, sampling the bottom sulcus F2F3 displays the most pathologic activity. SSMA = supplementary sensorimotor area. 
Interictal SEEG. A clearly pathological activity was recorded over the external contacts of electrode $\mathrm{H}$ exploring the inferior frontal sulcus in the premotor cortex (Figures 2A-D; $4 A, B)$. The normal background rhythms were replaced by moderate amplitude continuous spiking, with a maximum in the contacts exploring the sulcus' bottom raising suspicion of FCD (Figure 4B). During sleep runs of rapid spiking alternating with slowing were registered in this area. Similar spiking spread in remote areas, noncontiguous with the mesial frontal and parasagittal parietal territories.

Ictal SEEG recording. 18 short seizures (20-30 seconds) with stereotyped semiology, identical to those recorded during scalp video-monitoring sessions, were recorded. SEEG ictal episodes were preceded by increasing spiking frequency evolving into a low voltage fast activity with maximum tonicity in the electrode exploring dorsolateral premotor cortex. The network involved in seizure propagation activated SSMA, lateral and mesial motor cortex, and parasagittal parietal areas (Figure 5). Anterior cingulate, opercular, and mesial parietal areas were spared. Early postictal period showed high frequency bursts followed by suppression over the whole epileptogenic network. This EEG aspect suggested a FCD type II in the area of electrode $\mathrm{H}$ contacts 06-12.

Electrical signal analysis was performed at the University's Physics Department. Bi-dimensional maps of EEG amplitude (aEEG) in frequency of interest (FOI) bands were obtained based on contacts' stereotactic coordinates. The aEEG map of gamma frequencies points to the $\mathrm{H}$ electrode at seizure onset (Figure 7A-C, Supplementary material).

Electrical stimulation. Stimulation of the implanted structures was performed, aiming the study of the epileptogenic network, delineation of the eloquent cortex or inducing habitual seizures (5). Electrical stimuli $(1 \mathrm{~Hz}, 3 \mathrm{~ms}$ and $50 \mathrm{~Hz}, 1 \mathrm{~ms}$ rectangular biphasic pulses) were applied to adjacent contacts, using a programmable stimulator (Guideline $\mathrm{LP}+, \mathrm{FHC}$ Inc). The range of current intensity varied from 0.5 to $3 \mathrm{~mA}$, depending on the stimulated cortical area and on the evoked response. The low frequency protocol resulted in activation of the motor cortex and of the areas responsible for clonic movements of the contralateral hand and proximal part of the lower limb. The high frequency protocol elicited dizziness similar to the auras while stimulating contacts on the external part of the electrode exploring the dysplastic cortex with $1 \mathrm{~mA}$ current intensity; a full blown seizure was induced at $2 \mathrm{~mA}$ stimulation over the contacts recording from the inferior frontal sulcus (contacts $\mathrm{H} 6-\mathrm{H} 7$ ). External contacts of the same electrode were also stimulated while patient performed language tasks (loud counting, reading, object naming) and paraphasic speech was obtained, but no clear cut speech arrest. After 10 days of recordings and stimulations, the electrodes have been removed under local anesthesia. No complications occurred during or after the electrode implantation or removal.

Resection planning was based on non-invasive and invasive evaluation data, neuropsychology and patient's expectations. Critical information came from interictal depth recording showing epileptiform activity over the external contacts of $\mathrm{H}$ electrode as well as the seizure onset in the same region. Because no electrodes were placed in front and below this area (Broca area), it was decided a resection entirely limited to the borders of the explored pathologic area.

Surgery for focus removal was performed one month after the implantation. Patient refused surgery while awake (allowing additional intraoperative language and motor cortex and tracts mapping). Surgery was performed under general anesthesia with intraoperative mapping for motor function (evoked potentials) and stereotactic localization of the resection area. A $30 \mathrm{~mm}$ diameter cortectomy was performed in the dorsolateral premotor cortex, with no surgical complications (Figure 6B). The entire area of abnormal (gelatinous) macroscopic tissue was removed. The patient did not have postsurgical deficit and recovered completely.

During the 5 days after surgery, patient experienced several seizures while awake or in sleep. Medication was maintained (Lacosamide 200mg/day) and seizures stopped completely ever since. She is now in the $14^{\text {th }}$ month seizure free. EEG normalized.

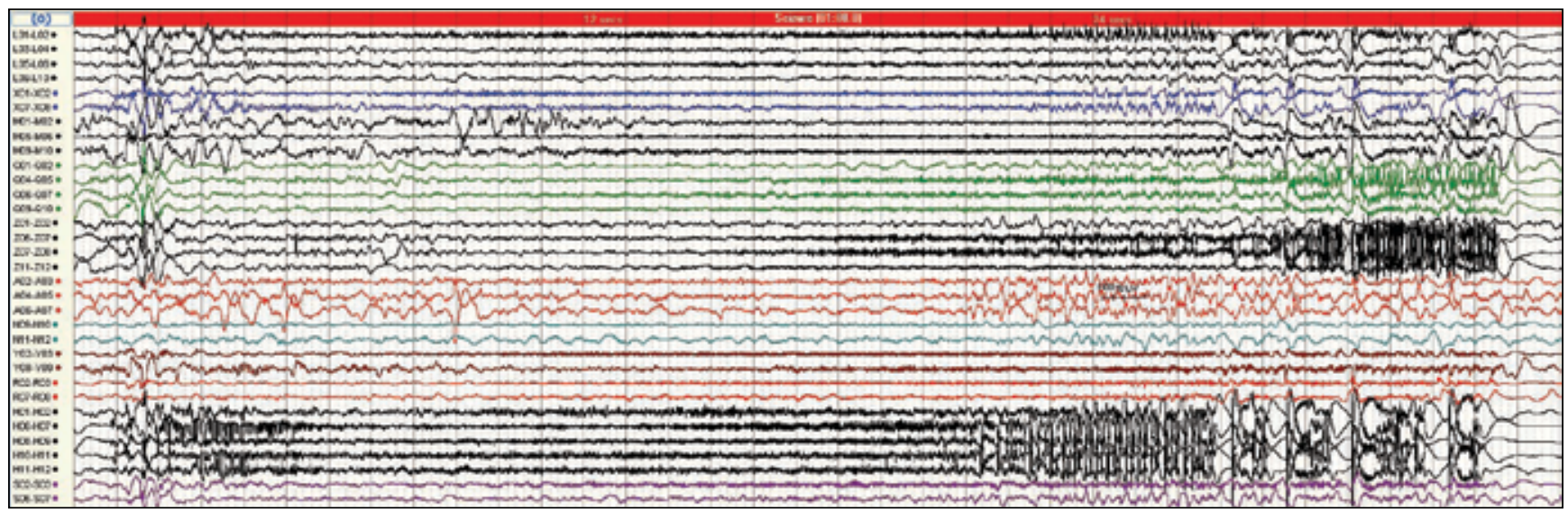

Figure 5: Ictal SEEG recording. 


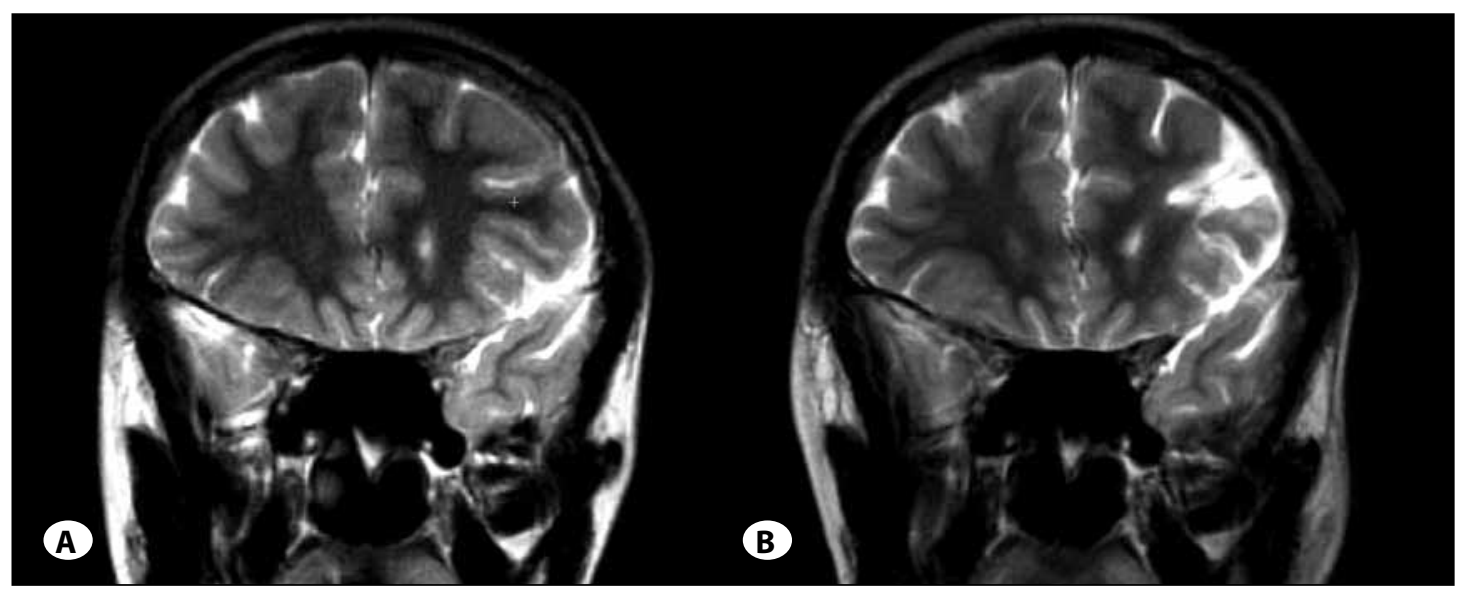

Figure 6: A) Presurgical MRI; B) Post-surgical MRI.

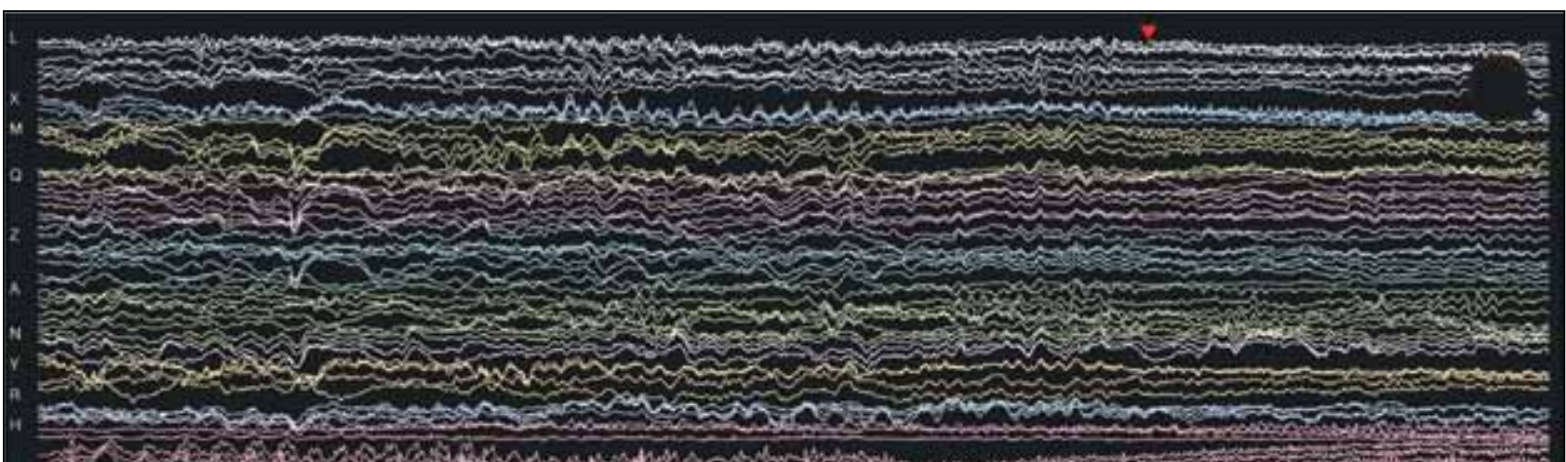

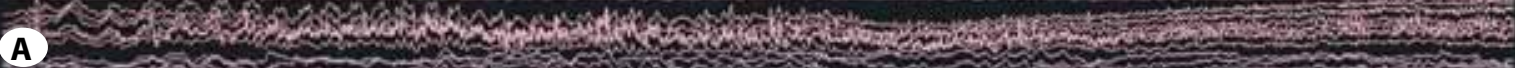
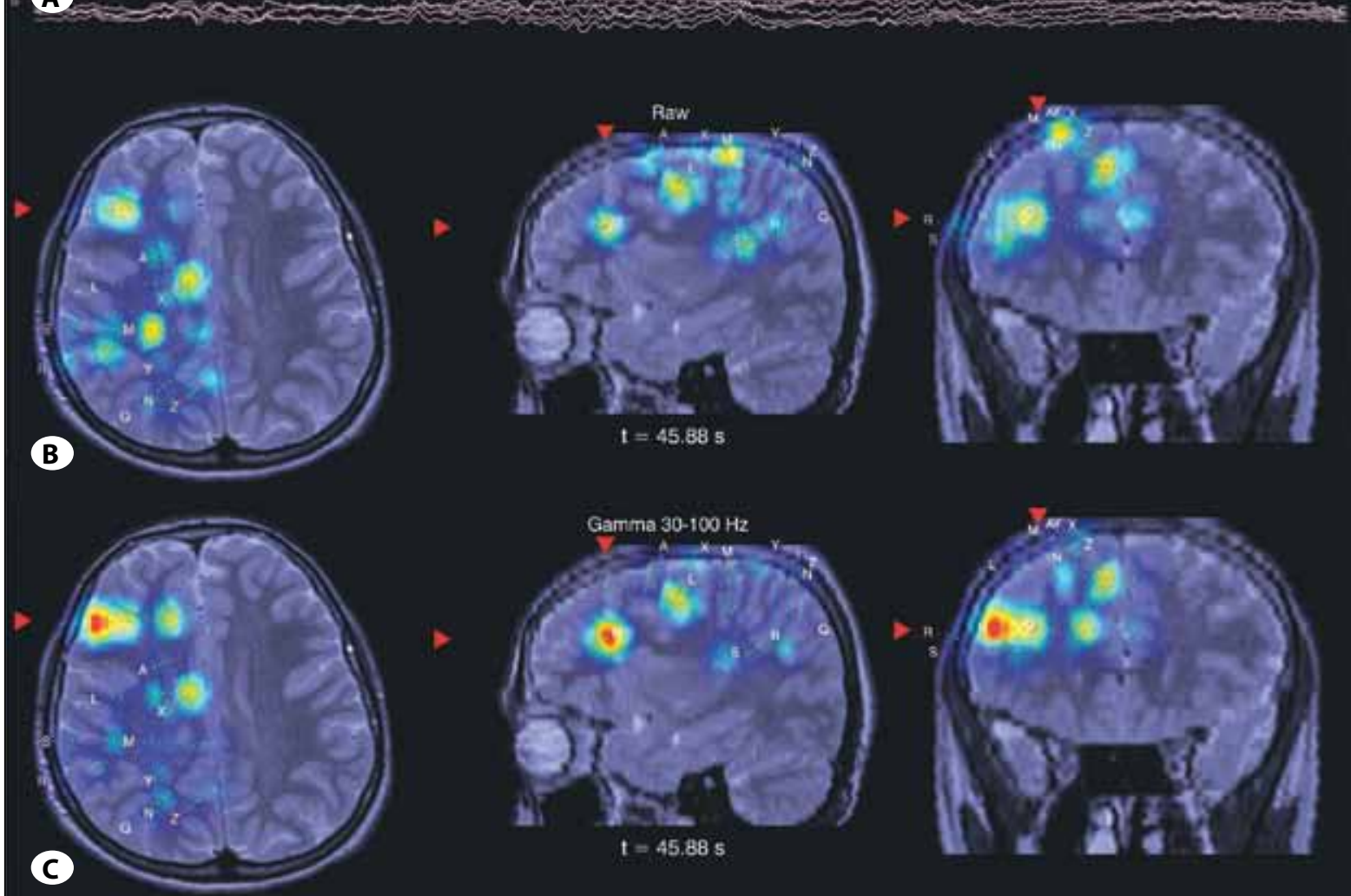

Figure 7: Spatial map of aEEG highlighting the seizure onset zone A) Raw traces of depth EEG recordings; B) Raw aEEG topographic map created using actual stereotactic coordinates of electrodes contacts; C) Gamma aEEG map. 


\section{DISCUSSION}

This was a difficult frontal epilepsy case in which SEEG clearly solved the preoperative dilemmas concerning seizures onset zone. Retrospective analyse of the surface EEG was concordant with the frontal seizure onset zone, but clinical signs at onset (sensitive symptoms at the onset of some seizures) raised doubts, suggesting parietal onset. These clinical signs were most probably due to rapid propagation of excitation to areas surrounding the dysplastic lesion using normal or pathological pathways (5).

Despite the fact that FCD was situated near eloquent cortex, SEEG method was highly accurate in delineating the resection area, preventing post-operative deficits.

The intracranial interictal electrical activity is typical for FCD type II b, recognized as a common cause of drug resistant epilepsy in pediatric population and commonly overlooked at routine inspection of MRI images, being considered MRI negative $(2,5)$.

An important limitation was related to the eccentric position of the electrode $\mathrm{H}$ in relation with the whole implantation scheme, without any sampling in front and below this area especially related to Broca's area in the inferior frontal gyrus tangential to the electrode H. 1.5T MRI and use of the classical epilepsy protocol may not be enough for FCDs detection, as already described in the literature (15).

Several seizures occurred in the next days after surgery, than completely stopped. This may suggest that either only the seizure onset zone was removed, but the whole epileptic network remained active for a short time, or a part of the dysplastic cortex remained in place. In the last circumstance, new aberrant synapses may lead to new seizures in time. The EEG aspect recorded both on surface and depth EEG resembles the electrophysiological behaviour similar to that of neurons in the thalamic reticular nucleus (Rt), aspect described in FCD type II (7).

\section{CONCLUSION}

This is a MRI-negative case of drug-resistant childhood epilepsy where SEEG method was invaluable in identifying the epileptogenic network and highly accurate in delineating area to be resected, minimizing the risk of post-operative deficits. Advanced 3D image processing techniques have been used to optimize the placement of depth electrodes in compliance with the vascular and anatomical constraints.

\section{ACKNOWLEDGMENTS}

Conflicts of Interest: Dr. D Craiu has received study bursary or lecture honoraria from Eli Lilly, Novartis, Pfizer and Desitin. Dr. A. Barborica has been receiving consulting fees and wages from FHC Inc, the manufacturer of the clinical stimulator and the planning software used in this study. Dr. I. Mindruta has received lecture honoraria from UCB Pharma, GlaxoSmithkline, Sanofi Aventis, Novartis, Pfizer and Desitin.
C Motoescu, C Donos, J Ciurea, have no conflict of interest to disclose.

Source of Funding: Application of the stereoelectroencephalographic procedure was partially funded from UEFISCDI PNII-ID-PCE-2011-3-0240.

\section{Legend for supplementary material}

First part: 3D view: coronal, axial and sagittal slices are swiped across the electrodes. Second part: Movie of the spatial distribution of aEEG highlighting the seizure onset zone. Raw traces of depth EEG recordings (upper part); Raw aEEG topographic movie created using actual stereotactic coordinates of electrodes contacts (lower part).

\section{REFERENCES}

1. Barborica A, Ciurea J, Mindruta I, Balanescu B, Donos C: A vascular safety index for stereotactic targeting of deep brain structures. Stereotact Funct Neurosurg 90 Suppl 1: 121, 2012

2. Chassoux F, Devaux B, Landré E, Turak B, Nataf F, Varlet $P$, Chodkiewicz JP, Daumas-Duport C: Stereoelectroencephalography in focal cortical dysplasia: A 3D approach to delineating the dysplastic cortex. Brain 123 (Pt 8):1733-1751, 2000

3. Cross JH, Jayakar P, Nordli D, Delalande O, Duchowny $M$, Wieser HG, Guerrini R, Mathern GW, International League against Epilepsy, Subcommission for Paediatric Epilepsy Surgery, Commissions of Neurosurgery and Paediatrics: Proposed criteria for referral and evaluation of children for epilepsy surgery: Recommendations of the Subcommission for Pediatric Epilepsy Surgery. Epilepsia 47(6): 952-959, 2006

4. Cuéllar R, Molinero M: Tratamiento de los niños con epilepsia de difícil control. Rev Neurol 37 (04):371-375, 2003

5. David O, Bastin J, Chabardès S, Minotti L, Kahane P: Studying network mechanisms using intracranial stimulation in epileptic patients. Front Syst Neurosci 4: 148, 2010

6. Frangi AF, Niessen WJ, Vincken KL, Viergever MA: Multiscale vessel enhancement filtering. In: Colchester A, Wells WM, Delp S (eds). MICCAI98 Medical Image Computing \& ComputerAssisted Intervention (Lecture Notes in Computer Science). New York: Springer-Verlag, 1998:130-137

7. Fuentealba P, Timofeev I, Bazhenov M, Sejnowski TJ, Steriade M: Membrane bistability in thalamic reticular neurons during spindle oscillations. J Neurophysiol 93(1): 294-304, 2005

8. Harvey AS, Cross JH, Shinnar S, Mathern GW, ILAE Pediatric Epilepsy Surgery Survey Taskforce: Defining the spectrum of international practice in pediatric epilepsy surgery patients. Epilepsia 49 (1):146-155, 2008

9. Hufnagel A, Poersch M, Elger CE, Zentner J, Wolf HK, Schramm $\mathrm{J}$ : The clinical and prognostic relevance of the postictal slow focus in the electrocorticogram. Electroencephalogr Clin Neurophysiol 94(1):12-18, 1995

10. Iliescu C, Burloiu C, Mincă DG: Epidemiological features of epilepsy in the pediatric population in Romania. Acta Medica Transilvanica 2(3):206-209, 2013

11. Jallon P: ILAE Workshop Report: Epilepsy in developing countries. Epilepsia 38(10):1143-1151, 1997 
12. Kahane $P$, Minotti L, Hoffmann D, Lachaux JP, Ryvlin P: Invasive EEG in the definition of the seizure onset zone: Depth electrodes. In: Rosenow F, Lüders HO (eds), Presurgical Assessment of the Epilepsies with Clinical Neurophysiology and Functional Imaging, Handbook of Clinical Neurophysiology. Vol 3, Amsterdam: Elsevier, 2004:109-133

13. Palmini A, Andermann F, Olivier A, Tampieri D, Robitaille $Y$, Andermann $\mathrm{E}$, Wright $\mathrm{G}$ : Focal neuronal migration disorders and intractable partial epilepsy: A study of 30 patients. Ann Neurol 30(6): 741-749, 1991
14. Sancho-Rieger J: Refractory epilepsy. Rev Neurol 51(5):320320, 2010

15. Tassi L, Garbelli R, Colombo N, Bramerio M, Russo GL, Mai R, Deleo F, Francione S, Nobili L, Spreafico R: Electroclinical, MRI and surgical outcomes in 100 epileptic patients with type II FCD. Epileptic Disord 14(3): 257-266, 2012 